\title{
Developing a Valid and Reliable Coping Self-Efficacy Scale (CSES) among Patients with Type 2 Diabetes: Iranian Version
}

\author{
Azar Tol'1, Bahram Mohebbi' ${ }^{2}$, Mostafa Hossaini' ${ }^{3}$, Fereshteh Majlessi ${ }^{{ }^{*}}$ \\ ${ }^{1}$ Department of Health Education and Promotion, School of Public Health, Tehran University of Medical \\ Sciences, Tehran, Iran \\ ${ }^{2}$ Hasheminejad Clinical Development Research Center, Hasheminejad Hospital, School of Medicine, \\ Iran University of Medical Sciences, Tehran, Iran \\ ${ }^{3}$ Department of Epidemiology and Biostatistics, School of Public Health, Tehran University of Medical Sciences, \\ Tehran, Iran \\ Email: ${ }^{*}$ dr_f_majlessi@yahoo.com
}

Received 21 January 2014; revised 21 February 2014; accepted 28 February 2014

Copyright (C) 2014 by authors and Scientific Research Publishing Inc.

This work is licensed under the Creative Commons Attribution International License (CC BY).

http://creativecommons.org/licenses/by/4.0/

(c) (i) Open Access

\begin{abstract}
Introduction: This study aimed to develop valid and reliable scale with the intention of measure Coping Self-efficacy (CSES) of Iranian type 2 diabetic patients. Patients and Methods: Validity and reliability of Iranian version of Coping Self-efficacy Scale (CSES) were measured by a cross-sectional study. Content validity, reliability and cultural equivalency were appraised through qualitative and quantitative study on 260 participants who have type 2 diabetes. Results: Reliability and validity of the scale and its four subscales, such as "stop unpleasant emotions and thoughts" $(\alpha=$ 0.92) "used problem-focused coping" $(\alpha=0.71)$, Self-efficacy on diabetes problem solving $(\alpha=0.74)$ and "get support from friends and family" $(\alpha=0.67)$ were approved explicitly by a psychometric analysis; these show that the scale was slightly valid and reliable on the study setting. An intraclass correlation coefficient was satisfactory $(p<0.001)$. Criterion validity between total scale and metabolic control Index (HbA1c) of type 2 diabetic patients was significant $(p<0.001)$ and showed indirect correlation with the domains of the scale. Conclusion: Study findings supported the reliability and validity of the Iranian version of new Coping Self-efficacy-24 for measuring Coping Selfefficacy among Iranian type 2 diabetic patients. Based on our finding, we would like to recommend appropriate interventions in the future.
\end{abstract}

\section{Keywords}

Coping Self-Efficacy; Type 2 Diabetes; Reliability; Validity; Iranian Version

\footnotetext{
*Corresponding author.
}

How to cite this paper: Tol, A., et al. (2014) Developing a Valid and Reliable Coping Self-Efficacy Scale (CSES) among Patients with Type 2 Diabetes: Iranian Version. Open Journal of Endocrine and Metabolic Diseases, 4, 45-51. 


\section{Introduction}

Type 2 diabetes is one of the major current chronic health problems around the world. The disease prevalence is rapidly increasing in both developing and developed countries [1] [2]. According to available information, approximately 54\% increase will occur in adult diabetic patients from 2010 to 2030 [3] throughout the world. Regarding the prevalence of diabetes in Iran, according to 2005 National Survey of Risk Factors for Non-Communicable Diseases of Iran, the prevalence rate of diabetes mellitus among 25 - 64-year-old Iranian citizens was estimated to be about $7.7 \%$ [4].

Patients with type 2 diabetes should be responsible for their day to day activities; and they should be accountable about their self-care behaviors towards diabetes [5]. It is important to note that effective adoption of diabetes self-management has an important role in diabetes control [6] [7]. As Chesney et al. (2006) represented, "this scale is designed to evaluate persons' confidence in performing coping behaviors when faced with life challenges” [8]. Coping is described as an individual's cognitive and behavioral attempts to control situation which can be stressful, when self-efficacy is delineated as person's belief which he/she has the capability to accomplish a specific behavior [8] [9]. The idea of the scale development was based on belief about person's ability to conduct special coping behaviors which influences interventions outcomes when intervention designed to improve coping [8]. The idea which compromises in this scale (coping self-efficacy) is a combination of two vital concepts in chronic situation and challenges, coping and self-efficacy which are both important matters living with type 2 diabetes. Because of chronicity of diabetic disease [1], patients need to adopt self-management behaviors to achieve desirable diabetes control [6] [7]. In order to do this, self-efficacy and coping have been confirmed by several studies to facilitate diabetes control goals separately, but there is no study which assesses the coping self-efficacy together; this is the innovation of current study to start a new paradigm to calculate this concept practically. Here, we assess some studies for two concepts. Several evidences could approve the role of self-efficacy among patients with type 2 diabetes as one of the main predictors of diabetes self-management behaviors adopting [6]. On the other hand, patients with type 2 diabetes as many chronic disease, suffer from different amount of distress related disease from mild to server based on stress continuum [10]. There are studies which represented decreasing diabetes stress can be practical with using coping strategies [11]. Since, it seems that coping Self-efficacy can be one of the main points of diabetes care because of rapid prevalence and incidence of diabetes in Iran [4], a great need for a valid and reliable scale for assessing psychosocial issues and interventional studies as Chesney et al. mentioned it as a specific character of the scale. As type 2 diabetes and its control are a big challenge among patients in their lives, we aimed to develop a valid and reliable scale with the intention of measuring Coping Self-efficacy (CSES) level of Iranian type 2 diabetes patients. Because, validation of scale which was developed by Chesney et al. (2006) seems to be a requisite in Iranian setup to conduct future interventions.

\section{Patients and Methods}

Two hundred and sixty (260) eligible diabetic patients were recruited through random sampling method to provide a maximum of ten respondents per each item on F-CSES-26 [12]. The participants were recruited from those referred at selected teaching hospitals of Tehran University of Medical Sciences. For ethical consideration, about nature and objectives of the study was checked by researchers who had experience on type 2 diabetes research. Regarding privacy, autonomy and right of participant were highly respected; and confidentiality of individual data was secured. The amount of recent $\mathrm{HbA}_{1 \mathrm{c}}$ results of patients was collected from the last medical record documents of each patient. This study was consists two types, which were qualitative and quantitative. To start work on original instrument, there was no need any permission of authors to use in research purposes as Cheseny et al. (2006) was indicated [8]. In qualitative section, translation and back translation process of the original version of CSE-26 was performed. Back translation reviewed by an independent group of experienced researchers and linguistics in order to achieve a modified version of the original scale. The translation group members were four researchers and two bilingual translators. They were checked and confirmed the provided translated version of F-CSES-26 as a complete representative one, in terms of phrasing and content as culturally and linguistically appropriate for Iranian diabetic patients. In order to obtain an agreement on the form and content of the translated version, Delphi method was used. Translated F-CSES-26 was sent to 10 academic members who were expert in instrument development and type 2 diabetes management. The analysis of version was assessed by researchers and revealed that, the version provided by Delphi method was almost completely the 
same as original scale in content. The organized version transferred to the expert panel included 4 person separately which were responsible to develop final version of F-CSES-26. Finally, content validity of F-CSES-26 was conducted by the panel included one Endocrinologists, two diabetes educators and one health education and promotion specialist. The original F-CSES-26 and the version which prepared by expert panel were resent to each panel member who were bilingual. Again content validity was reevaluated by requesting the panel members to rate level of each item of the construct using 11-point scale with three anchor points zero ("cannot do at all”), 5 ("moderately certain can do"), and 10 (“certain can do"). A content validity ratio was calculated for each item and for the whole F-CSES-26 scale. Moreover, the panel was inquired to comment on individual items in relation to the accuracy simplicity, style, and cultural relevance of the final translation. Minor changes were recommended. Finally, panel-modified version of instrument was developed after including comments from panel. In quantitative part of the study, final version was piloted, meanwhile the needed corrections were done, and post pilot version was got ready for main evaluation. Finally, it was applied for study participant. As a result, the validity (construct, criterion and internal) and reliability (through internal consistency) were accomplished. Participants in the pilot study remarked on some phrasing in some of the items including "negative situation and emotional social support". Some participant were request more description about psychosocial concepts in their day-to-day living activists. Then, more clarifications and explanations were provided; and the explanation was helped them to respond easily. In average 10 - 15 minutes was required to fill out all items of the instrument. The collected data were analyzed using SPSS version 11.5. According to, the assessment, construct validity and suitability of the data for factor analysis were checked using the Kaiser-Mayer-Olkin (KMO) measure of sampling adequacy of 0.5 and Bartlett's chi-square test of Sphericity with $p<0.05$ [13]. The new dimensional structure of the CSES were confirmed with an EFA by the principal component extraction method using a Varimax rotation with Kaiser normalization as a usual descriptive method for analyzing grouped data [14]. These criteria which were followed: 1) Eigen value $>1$ [15], 2) Loading level greater than 0.50 to assess whether an item loaded on one factor or the others [16], and 3) the description of the factor structure should be significant [17]. Also, Pearson correlation coefficient was used to evaluate criterion validity between total scale and metabolic control $\left(\mathrm{HbA}_{1 \mathrm{C}}\right)$ of participants. The significance level was set at $p<0.01$.

\section{Results}

The study sample consisted of 260 patients and response rate was $90.1 \%$. The majority of the patients were aged about 60 years old (60.32 (10.65), [mean (SD)]), and more than half of them diagnosed as diabetic patients during the past 7 years ( $7.47 \pm 6.49$ [mean, SD]), and (66.2\%) determined borderline metabolic control according to World Health Organization criteria [10] (8.01 \pm 1.20 [mean, SD]). Table 1 shows the Socio demographic and

Table 1. Socio demographic and Health-related Characteristics of participants.

\begin{tabular}{|c|c|c|c|}
\hline Variables & Frequency (\%) & Variables & Frequency (\%) \\
\hline $\begin{array}{l}\text { Age (yrs.) } \\
\quad<50 \\
\geq 50\end{array}$ & $\begin{array}{l}136(52.3) \\
124(47.7)\end{array}$ & $\begin{array}{c}\text { Family Income } \\
\text { low } \\
\text { Middle } \\
\text { High }\end{array}$ & $\begin{array}{c}70(26.9) \\
177(68.1) \\
13(5)\end{array}$ \\
\hline $\begin{array}{l}\text { Sex } \\
\text { Male } \\
\text { Female }\end{array}$ & $\begin{array}{l}124(47.7) \\
136(52.3)\end{array}$ & $\begin{array}{l}\text { Duration of diabetes (yrs.) } \\
\qquad \begin{array}{c}<5 \\
\geq 5\end{array}\end{array}$ & $\begin{array}{l}131(50.4) \\
129(49.6)\end{array}$ \\
\hline $\begin{array}{l}\text { Level of education } \\
\text { Illiterate } \\
\text { Up to diploma } \\
\text { Diploma } \\
\text { Postgraduate }\end{array}$ & $\begin{array}{l}109(41.9) \\
110(42.3) \\
32(12.3) \\
9(3.5)\end{array}$ & $\begin{array}{l}\text { Type of treatment } \\
\text { Oral Agents } \\
\text { Insulin } \\
\text { Oral Agents \& Insulin }\end{array}$ & $\begin{array}{l}172(66.1) \\
53(20.4) \\
35(13.5)\end{array}$ \\
\hline $\begin{array}{l}\text { Marital Status } \\
\text { Married } \\
\text { Unmarried }\end{array}$ & $\begin{array}{c}225(86.5) \\
35(13.5)\end{array}$ & $\begin{array}{c}\text { History of Type2 Diabetes } \\
\text { Yes } \\
\text { No }\end{array}$ & $\begin{array}{l}128(49.2) \\
132(50.3)\end{array}$ \\
\hline $\begin{array}{l}\text { History of other chronic disease } \\
\text { Yes } \\
\text { No }\end{array}$ & $\begin{array}{c}165(63.5) \\
95(36.5)\end{array}$ & $\begin{array}{c}\text { Metabolic control(HbA1C) } \\
\text { Optimal control }(<7.0 \%) \\
\text { Borderline control }(7.0 \%-8.5 \%) \\
\text { Poor Control }(>8.5 \%)\end{array}$ & $\begin{array}{c}40(15.4) \\
172(66.2) \\
48(18.5)\end{array}$ \\
\hline
\end{tabular}


Health-related Characteristics among study participants (Table 1). "Stop unpleasant emotions and thoughts about diabetes" proved as the most important subscales among others analyzed by factor analysis. Eigen value for domains was showed in Table 2. It is important to notice that this scale divided into 4 subscales versus three of them were from the original scale. Also, Table 2 shows, that the descriptive statistics of all subscales. To identify the performance and overall internal consistency of each subscale, item statistics were conducted and shown that the decrement of overall internal consistency of subscales. Based on factor analysis results, two questions were omitted (items 13 and 24). Reliability of F-CSES-24 scale was assessed and the Cronbach $\alpha$ was 0.90 (90\%). The rate of $\alpha$ Cronbach among the subscales was ranged from 0.67 to 0.92 . Spearman correlation coefficient was used to demonstrate the reliability of item domains; such as "Stop unpleasant emotions and thoughts", "Use problem-focused coping", "Self-efficacy on problem solving” and "get support from friends and family"; and their Cronbach $\alpha$ were 0.92, 0.71, 0.74 and 0.67 respectively. Table 3 shows clearly, items analysis and reliability of the F-CSES-24.

Table 4 demonstrated exploratory factors and explained variance after rotation for F-CSES-24. A significant

Table 2. Descriptive statistics of F-CSES-24 and subscale.

\begin{tabular}{ccccc}
\hline Domains & Number of items & Means \pm SD (Range) & Eigen Value & Variance (\%) \\
\hline Stop unpleasant emotions and thoughts & 10 & $47.45 \pm 19.78(5-95)$ & 8.24 & 31.71 \\
Use problem-focused coping & 5 & $27.51 \pm 8.02(0-47)$ & 28 & 1.63 \\
Self-efficacy on diabetes problem solving & 5 & $24.67 \pm 7.83(0-47)$ & 1.42 \\
Get support from friends and family & 4 & $113.29 \pm 1.69(30-223)$ & - \\
\hline
\end{tabular}

Table 3. Item analysis and reliability of the F-CSES-24 after back translation.

\begin{tabular}{|c|c|c|c|c|c|}
\hline Items & Mean & SD & $\begin{array}{l}\text { Item total } \\
\text { correlation }\end{array}$ & $\begin{array}{c}\text { Cronbach's } \\
\text { alpha }\end{array}$ & ICC \\
\hline \multicolumn{6}{|l|}{ Stop unpleasant emotions and thoughts about diabetes } \\
\hline 10. Take your mind off unpleasant thoughts. & 43.30 & 29.56 & 0.886 & \multirow{10}{*}{0.92} & \multirow{10}{*}{0.92} \\
\hline 12. Keep from feeling sad. & 42.89 & 30.31 & 0.838 & & \\
\hline 7. Leave options open when thing stressful. & 42.59 & 32.09 & 0.758 & & \\
\hline 19. Make unpleasant thoughts go away. & 42.78 & 31.07 & 0.758 & & \\
\hline 15. Stop yourself from being upset by unpleasant thoughts. & 42.84 & 32.04 & 0.637 & & \\
\hline 1. Keep from getting down in the dumps. & 41.99 & 32.53 & 0.650 & & \\
\hline 25. Stand your ground and fight for what you want. & 41.84 & 32.71 & 0.620 & & \\
\hline 8. Make a plan of action and follow it when confronted with a problem. & 42.60 & 33.57 & 0.610 & & \\
\hline 9. Develop new hobbies $r$ recreations. & 43.39 & 32.57 & 0.651 & & \\
\hline 11. Look for something good in a negative situation. & 42.78 & 33.76 & 0.615 & & \\
\hline \multicolumn{6}{|l|}{ Use problem-focused coping } \\
\hline 3. Sort out what can and cannot be changed. & 26.31 & 49.90 & 0.597 & \multirow{5}{*}{0.71} & \multirow{5}{*}{0.70} \\
\hline 6. Break an upsetting problem down into smaller parts. & 26.30 & 51.05 & 0.528 & & \\
\hline 2. Talk positively to yourself. & 26.06 & 43.97 & 0.498 & & \\
\hline 5. Find solutions to your most difficult problems. & 26.08 & 49.57 & 0.498 & & \\
\hline 26. Resist the impulse to act quickly when under pressure. & 27.27 & 57.78 & 0.237 & & \\
\hline \multicolumn{6}{|l|}{ Self-efficacy on diabetes problem solving } \\
\hline 20. Think about one part of the problem at a time. & 19.85 & 41.85 & 0.556 & \multirow{5}{*}{0.74} & \multirow{5}{*}{0.74} \\
\hline 14. Try other solutions to your problems if your first solutions don't work. & 19.66 & 40.90 & 0.578 & & \\
\hline 18. Try to do something positive for yourself when you are feeling depressed. & 19.67 & 39.31 & 0.476 & & \\
\hline 21. Pictured a pleasant activity. & 19.99 & 43.46 & 0.553 & & \\
\hline 22. Keep yourself from feeling lonely. & 19.52 & 43.43 & 0.389 & & \\
\hline \multicolumn{6}{|l|}{ Get support from friends and family } \\
\hline 16. Make new friends. & 21.68 & 40.05 & 0.416 & \multirow{4}{*}{0.67} & \multirow{4}{*}{0.67} \\
\hline 23. Pray or meditate. & 21.69 & 41.95 & 0.516 & & \\
\hline 17. Get friends to help with the thing you need. & 22.96 & 38.73 & 0.481 & & \\
\hline 4. Get emotional support from family and friends. & 21.20 & 49.64 & 0.250 & & \\
\hline Total & & & & 0.90 & 0.90 \\
\hline
\end{tabular}


Table 4. Exploratory factors and explained variance after rotation for F-CSES-24.

\begin{tabular}{|c|c|c|c|c|c|}
\hline \multirow{2}{*}{ Subscales } & \multirow{2}{*}{ Item No. } & \multicolumn{4}{|c|}{ Factors } \\
\hline & & 1 & 2 & 3 & 4 \\
\hline \multirow{12}{*}{ Stop unpleasant emotions and thoughts } & 10 & 0.887 & & & \\
\hline & 12 & 0.864 & & & \\
\hline & 7 & 0.784 & & & \\
\hline & 19 & 0.750 & & & \\
\hline & 15 & 0.695 & & & \\
\hline & 1 & 0.684 & & & \\
\hline & 25 & 0.683 & & & \\
\hline & 8 & 0.671 & & & \\
\hline & 9 & 0.654 & & & \\
\hline & 11 & 0.552 & & & \\
\hline & 3 & & 0.813 & & \\
\hline & 6 & & 0.730 & & \\
\hline \multirow[t]{5}{*}{ Use problem—focused coping } & 2 & & 0.681 & & \\
\hline & 5 & & 0.627 & & \\
\hline & 26 & & 0.606 & & \\
\hline & 20 & & & 0.717 & \\
\hline & 14 & & & 0.630 & \\
\hline \multirow[t]{4}{*}{ Self-efficacy on diabetes problem solving } & 18 & & & 0.578 & \\
\hline & 21 & & & 0.525 & \\
\hline & 22 & & & 0.517 & \\
\hline & 16 & & & & 0.740 \\
\hline \multirow{3}{*}{ Get support from friends and family } & 23 & & & & 0.740 \\
\hline & 17 & & & & 0.663 \\
\hline & 4 & & & & 0.798 \\
\hline Eigen values & & 8.24 & 3.28 & 1.89 & 1.42 \\
\hline Variance accounted for & & 31.71 & 12.63 & 7.27 & 5.48 \\
\hline
\end{tabular}

negative correlation was found between total coping Self-efficacy score and $\mathrm{HbA}_{1} \mathrm{c}$ among the respondents $(r=$ $-0.33, p<0.001)$. After controlling the effects of age, educational level, and duration of having diabetes, the correlation between total coping Self-efficacy score and $\mathrm{HbA}_{1} \mathrm{c}$ were remained significant $(p<0.001)$.

\section{Discussion}

Findings of the study were not completely supported the construct validity and test-retest of the original CSES. Based on our findings, we were changed two items, such as "leave options open when things get stressful” and "visualize a pleasant activity or place", which were omitted from the original scale. Third subscale was taken as separate one subscale, and one domain was added based on results from factor analysis. Contrarily, because of cultural diversity of Iranian and nature of diabetic disease, results from this study were acceptable.

Self-efficacy on diabetes problem solving Subscale, which contains items with self-efficacy concepts with problem solving strategies were approved as a domain itself. Justification of this finding may be due to the importance of self-efficacy concept and problem solving strategies in diabetes management as proved in several study in Iran [5]-[7]. 
The coefficient for the four main subscales and the total F-CSES-24 were satisfactory. The test-retest reliability of the F-CSES-24 was supported by $\alpha$ Cronbach of the subsample of 260 patients and was $90 \%$.

It is important to note that this scale was validated by Ludae in Latvia (2011); and our study was revealed some changes which make different from Ludae [18]. However, this study didn't well identify its targeted population whether conducted on type 2 or other study population. This difference was may be due to cultural difference of the two countries population. Additionally, it is important to understand that, the first subscale "Stop unpleasant emotions and thoughts" was achieved more Eigen value than the others which was not the same with original scale. On this point our finding was support the other researchers' findings and was concentrated theory based intervention according to diabetic management studies. On the other hand, "Self-efficacy on diabetes problem solving" was approved the necessity of consideration of self-efficacy using theories separately or in combinations.

Based on our finding we would like to recommend the importance of application of this scale for diabetes behavioural based research; because the importance of psychological viewpoints in diabetes self-management has been highly recommended by numerous researches [6] [7] [19]-[24]. Several studies were detected that, Selfmanagement behaviors help to copes with the challenges faced in diabetes control [25]. As Chesney et al. scale was demonstrated the ability of this instrument in behavioral intervention is very important. Similarly, this study was revealed the importance of Iranian version scale of the instrument in diabetes management intervention. This study was revealed that, using of the scale is easy; and its generalizability depends on sample size and study population characteristics.

\section{Conclusion}

Despite that the slightly strong validity and reliability have been revealed on the evaluation of Iranian version of F-CSES-24 scale and similarity with Chesney et al. scale, the original scale, we were unable to compare our study with similar studies because of lack of similar studies which evaluate the scale on type 2 expect one study conducted by Ludae in Latvia (2011). Therefore, our study was supported with the helpfulness of F-CSES-24 scale in determination of total coping self-efficacy score and related domains to provide more appropriate, relevant educational materials and to set suitable health promotion intervention programs among type 2 diabetic patients.

\section{Acknowledgments}

The authors express their gratitude to all participants; without their enthusiastic collaboration, this study would not have been possible. This study was funded through research grant number 21354 by Tehran University of Medical Sciences. The authors declare that they have no conflicts of interests.

\section{References}

[1] Wild, S., Roglic, G., Green, A., Sicree, R. and King, H. (2004) Global Prevalence of Diabetes. Diabetes Care, 27, 1047-1053. http://dx.doi.org/10.2337/diacare.27.5.1047

[2] Spinaci, S., Currat, L., Shetty, P., Crowell, V. and Kehler, J. (2006) Tough Choices: Investing in Health for Development: Experiences from National Follow-Up to Commission on Macroeconomics and Health. WHO Report.

[3] International Diabetes Federation (2009) Diabetes Atlas. 4th Edition, IDF.

[4] Esteghamati, A., Gouya, M.M., Abbasi, M., Delavari, A., Alikhani, S., Alaedini, F., et al. (2008) Prevalence of Diabetes Mellitus and Impaired Fasting Glucose in the Adult Population of Iran: National Survey of Risk Factors for Non-Communicable Diseases of Iran. Diabetes Care, 31, 96-98. http://dx.doi.org/10.2337/dc07-0959

[5] Funnell, M.M. and Anderson, R.M. (2000) The Problem with Compliance in Diabetes. JAMA, 284, 1709. http://dx.doi.org/10.1001/jama.284.13.1709

[6] Tol, A., Shojaeezadeh, D., Sharifirad, G.R., Eslami, A.A., Alhani, F. and Mohajeri Tehrani, M.R. (2012) Predictors of Self-Management Behaviors among Type 2 Diabetes Patients. Journal of Basic and Applied Sciences, 2, 2270-2274.

[7] Baghbanian, A. and Tol, A. (2012) The Introduction of Self-Management in Type 2 Diabetes Care: A Narrative Review. Journal of Education and Health Promotion, 1, 1-5.

[8] Chesney, M.A, Neilands, T.B., Chambers, D.B., Tylor, J.M. and Folkman, S. (2006) A Validity and Reliability Study of the Coping Self-Efficacy SCALE. British Journal of Health Psychology, 11, 3421-437. 
http://dx.doi.org/10.1348/135910705X53155

[9] Benight, C.C. and Harper, M.L. (2002) Coping Self-Efficacy Perceptions as a Mediator between Acute Stress Response and Long-Term Distress Following Natural Disasters. Journal of Traumatic Stress, 15, 3177-186. http://dx.doi.org/10.1023/A:1015295025950

[10] Tol, A., Baghbanian, A., Sharifirad, G., Shojaeizadeh, D., Eslami, A.A., Alhani, F. and Tehrani, M.M. (2012) Assessment of Diabetic Distress and Disease Related Factors in Patients with Type 2 Diabetes in Isfahan: A Way to Tailor an Effective Intervention Planning in Isfahan-Iran. Journal of Diabetes and Metabolic Disorders, 11, 1-5.

[11] Huang, M.F., Courtney, M., Edwards, H. and McDowell, J. (2010) factors That Affect Health Outcomes in Adults with Type 2 Diabetes: A Cross-Sectional Study. International Journal of Nursing Studies, 47, 542-549. http://dx.doi.org/10.1016/j.ijnurstu.2009.10.012

[12] Streiner, D.L. and Norman, G.R. (1995) Health Measurement Scales: A Practical Guide to Their Development and Use. 2nd Edition, Oxford UniversityPress, Oxford.

[13] Kaiser, H.F. (1974) An Index of Factorial Simplicity. Psychometrika, 39, 131-36. http://dx.doi.org/10.1007/BF02291575

[14] Dixon, J.K. (2005) Exploratory Factor Analysis. In: Munro, B., Ed., Statistical Methods for Health Care Research, Lippincott Williams \& Wilkins Publisher, Philadelphia, 321-349.

[15] Kaiser, H.F. (1960) The Application of Electronic Computers to Factor Analysis. Educational and Psychological Measurement, 20, 141-151. http://dx.doi.org/10.1177/001316446002000116

[16] Costello, A.B. and Osborne, J.W. (2007) Best Practices in Exploratory Factor Analysis: Four Recommendations for Getting the Most from Your Analysis. Practical Assessment Research and Evaluation, 10, 1-9. http://pareonline.net/pdf/v10n7.pdf

[17] Hakstian, A.R., Rogers, W.D. and Cattell R.B. (1982) The Behavior of Numbers Factors Rules with Simulated Data. Multivariate Behavioral Research, 17, 193-219. http://dx.doi.org/10.1207/s15327906mbr1702_3

[18] Ludane, M. (2011) Adaptation of Coping Self-Efficacy Scale in Latvian. 11th European Conference on Psychological Assessment, Riga.

[19] Schilling, E.J. and Park, C.L. (2005) Effects of Stress, Coping and Other Psychological Factors on the Health of Individuals with Diabetes. In: Lee, A.V., Ed., Coping with Disease, Nova Science Publishers, New York, 65-80.

[20] Chouhan, V.L. and Vyas, S. (2006) Coping Strategies for Stress and Adjustment among Diabetics. Journal of the Indian Academy of Applied Psychology, 32, 143-149.

[21] Coelho, R., Amorim, I. and Prata, J. (2003) Coping Styles and Quality of Life in Patients with Non-Insulin Dependent Diabetes Mellitus. Psychosomatics, 44, 312-318. http://dx.doi.org/10.1176/appi.psy.44.4.312

[22] Sanden-Eriksson, B. (2000) Coping with Type 2 Diabetes: The Role of Sense of Coherence Compared with Active Management. Journal of advance Nursing, 31, 1393-1397.

[23] Kanbara, S., Taniguchi, H., Sakaue, M., Wang, D., Takaki, J., Yajima, Y., et al. (2008) Social Support, Self-Efficacy and Psychological Stress Responses among Outpatients with Diabetes in Yogyakarta, Indonesia. Diabetes Research and Clinical Practice, 80, 56-62. http://dx.doi.org/10.1016/j.diabres.2007.12.015

[24] Tol, A., Shojaeizadeh, D., Sharifirad, G., Eslami, A.A., Alhani, F. and Mohajeri Tehrani, M.R. (2012) EmpowermentBased Diabetes Self-Management Intervention Program among Type 2 Diabetic Patients in Isfahan, A Big Province of Iran. Fauna Rossii I Sopredel Nykh Stran, 8, 1-8.

[25] Anderson, R. and Funnell, M. (2000) Compliance and Adherence Are Dysfunctional Concepts in Diabetes Care. Diabetes Education, 26, 597-604. http://dx.doi.org/10.1177/014572170002600405 